\title{
ELEMENTAL COMPOSITION OF BIODIESEL PRODUCED BY FAST PYROLYSIS OF EUCALYPTUS LEAVES
}

\section{DOI : 10.36909/jer.ICIPPSD.15525}

\author{
Ashok Patel * , Basant Agrawal**, B R Rawal** \\ *Research scholar, S.G.S.I.T.S., Indore (M.P.), India \\ ${ }^{* *}$ Professor, S.G.S.I.T.S., Indore (M.P.), India \\ *Email: ashokpatel678@gmail.com; Corresponding Author.
}

\begin{abstract}
In this study, temperature studies were studied on the production of a product from selected eucalyptus leaving samples. The bio-diesel yield from these samples was further determined using non-model methods and analytical pyrolysis-gas chromatography / mass spectrometry (Py-GC/ MS). The fresh eucalyptus leaves were obtained from nearby forest of Godhra (Gujarat), India. Results of the Proximate analysis of eucalyptus leaves powder sample study shows that volatile matter, fixed carbon, ash content and moisture content are $61.70 \%, 26.37 \%, 8.36 \%$ and $3.57 \%$, The results of the basic analysis indicate that the carbon, hydrogen, nitrogen, oxygen, and sulfur content is $89.17 \%$, $7.36 \%, 1.01 \%, 1.98 \%$ and $0.26 \%$, respectively. The higher heating value (HHV) of the biodiesel obtained from the biomass samples is $32.81 \mathrm{MJ} / \mathrm{kg}$. Chemical composition analysis of Eucalyptus Biodiesel carried out and compared with standards. The study revealed that pyro-fuel is not only used as fuel but also can be purified and used as a commodity in the chemical and processing industries.
\end{abstract}

Keywords - Analytical pyrolysis, Biomass, GC-MS analysis, Proximate analysis, Ultimate analysis.

\section{INTRODUCTION}

Thermochemical conversion of lignocellulosic materials is getting attraction a mong researchers and industrialists due to its large number of benefits over biochemical transformation methods(Patel, Agrawal, and Rawal 2020). Considering safe environment and high demand of renewable energy, biomass has received great attention. Biomass is pure and has a low content of sulfur, nitrogen, and 
ash, so it provides lower emissions of sulfur oxides $\left(\mathrm{SO}_{\mathrm{x}}\right)$, nitrogen oxides $\left(\mathrm{NO}_{\mathrm{x}}\right)$ and auxiliary compared to conventional fossil fuels. It is likely that carbon dioxide $\left(\mathrm{CO}_{2}\right)$ emissions can be detected as $\mathrm{CO}_{2}$ emitted from biomass is reused in plants by mass photosynthesis (Balat et al. 2009; Zhang, Xu, and Champagne 2010).

For converting biomass into physical, biological ,thermal and energy conversion processes like direct pyrolysis, combustion and gasification are used (Suttibak 2017). During pyrolysis process, primary and secondary type of reactions involving free radicals takes place (Oyebanji et al. 2018). The said process can be categorized in terms of flash, fast and slow based on temperature, heating rate and residence time. In the flash pyrolysis process, quick heating is done between the temperature range of 400 to $900{ }^{\circ} \mathrm{C}$. On the other hand, fast pyrolysis temperature is kept below $600{ }^{\circ} \mathrm{C}$ and heating rate is kept low. Whereas, the slow pyrolysis, as its name indicates, performed at even lower heating rate at the temperature between 450 to $700{ }^{\circ} \mathrm{C}$. The basic elements produced in the pyrolysis process are char, oil and gas. Char, which is in the solid form is used in combustion process or acts as an activated carbon in food industry or waste treatment plants. The combustible gas is consumed for energy production purpose. The pyrolysis oil which is in the liquid form, consisting of variety of organic compounds which can perform various chemical functions(Oyebanji et al. 2018). Bio-oil can be considered as a fuel having a potential which can be used directly or can be used as a highpotential chemical source. Comparatively, less research problems have been addressed related to biomass in India(Onsree et al. 2018). It is witnessed that advanced biofuels are getting preferred in India which are used in organic and thermal conversion procedures will be considered as a potential of lignocellulosic properties for the sustainable making of biofuels and bio-chemicals in future.

The use of agricultural forest waste such as eucalyptus leaves produces significant waste and contributes to environmental pollution because the most common way of disposing of such waste is open heat or petrol wood in the form of sawdust wood for home cooking and cooking. Exhaust fumes, carbon dioxide and other greenhouse gases increase in open heat which is one of the main causes of pollution and health risks. The alteration of biomass waste into energy also provides a chance for improved waste management while at the same time generating clean energy. Researchers in India are making efforts to study the pyrolysis process for the production of bio oil from a different feedstock (Purohit and Chaturvedi 2018; Joshi, Sharma, and Manab Sarma 2015; Kaushik and Singh 2016). Moussa et al. read the parameters affecting the aldehydes extracted from Ethanol engines using the improved CHEMKIN-PRO simulation system.(Moussa and Alzeibak 2014) 
In this research work, the thermal performance was studied in the products of the eucalyptus product that left samples. The bio-diesel yield from these samples was further determined using non-model methods and analytical pyrolysis-gas chromatography / mass spectrometry (Py-GC / MS).

\section{MATERIALS AND METHODS}

\section{Collection of biomass samples}

The fresh eucalyptus leaves were obtained from nearby forest of Godhra (Gujarat), India. After collecting the eucalyptus leaves, they were dried at an environmental temperature for 7 to 10 days. The materials used as biomass was dry eucalyptus leaves, so it has higher potential for inclusion in the sustainable bio-diesel production. Dry leaves of eucalyptus were crushed in to crusher with required size before supplying to pyrolysis reactor for experiments. The classification of samples of biomass was according to size of eucalyptus leaves after crushing.

\section{Proximate analysis}

Proximate analysis is a standardized procedure which indicates the bulk components present in fuel. It was done to find out the average percentage of the fixed carbon, volatiles, ash and moisture content in solid fuel by weight. The procedure of ASTM standard D5373-02 (2003) was followed to obtain the above parameters of eucalyptus leaves powder.

\section{Ultimate Analysis}

The ultimate analysis indicates the various elemental chemical constituents such as Carbon $(C)$, Oxygen(O), Sulphur(S), Hydrogen(H), etc. CHN/S/O Analyzer, Parkin Elmer, Seies II, 2400 test was used for getting results of raw material (solid type) for ultimate analysis (\% by weight- dry basis) with Eucalyptus leaf powder.

\section{Experimental set-up}

Figure 1 shows the experimental setup used in the pyrolysis test. Contains a cylindrical reactor made of carbon steel (750-gram capacity), 5-kW heating device with automatic temperature control, condenser, vacuum pump and liquid collector. Bio oil was produced by rapid pyrolysis of eucalyptus leaves using a vacuum level of 10-1 torr to remove all oxygen present inside the reaction. The circular structure formed by the sample was made inside the filter paper from (filter paper as the side 
wall of the sample block to keep the biomass stable), while the weight of this sample was kept at 450 grams.

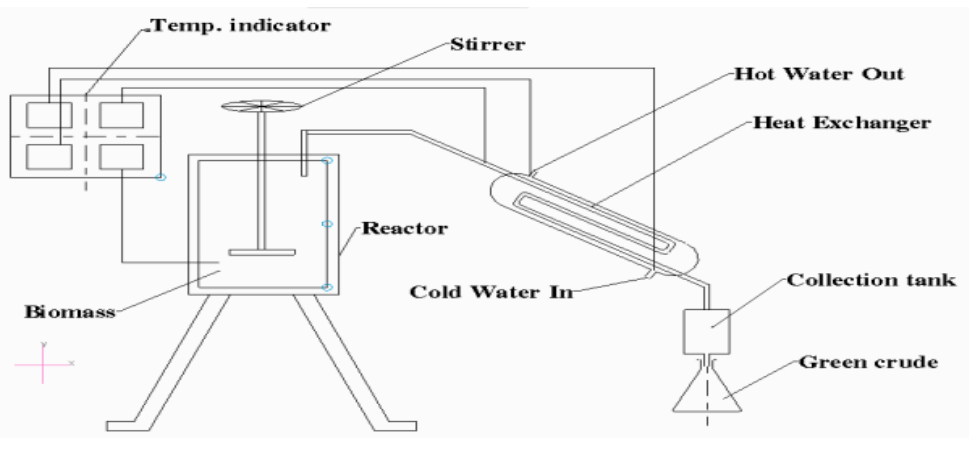

Fig.1: Layout of Experimental setup of fast pyrolysis.

\section{Gas chromatography-mass spectrometry analysis}

Analysis of compounds present in biodiesel was conducted by Gas chromatography- mass spectrometry (GC-MS) instrument to find the lignin and extractive contents.

\section{Specifications:}

\begin{tabular}{|l|l|}
\hline Analyzer: & Quadrupole with pre filter \\
\hline Mass Range: & 20-620 Daltons (amu) \\
\hline Mass Stability: & $\pm 0.1 \mathrm{~m} / \mathrm{z}$ mass accuracy over 48 hours \\
\hline Ionization Modes: & EI/CI Ionization. \\
\hline Vacuum Pump: & Turbo molecular pump 250L/Sec. \\
\hline Software: & Turbo Mass \\
\hline Model: & Auto system XL GC with turbomass \\
\hline Make: & Perkin Elmer \\
\hline
\end{tabular}

The GC-MS mainly consists of the Perkin Elmer Auto system XL gas chromatograph and the final phase as a large spectrometer. Mass spectrometry is a method of classifying ions or atoms in a computer by mass. This is achieved by dismantling the sample molecules and accelerating them through an electric field. These charged particles are then introduced into the magnetic field where they often deviate in different directions in terms of their magnitude $(\mathrm{m})$ charge $(\mathrm{Z})$ ratio $(\mathrm{m} / \mathrm{z})$. This will reveal many samples. Mass spectra helps to confirm the atomic structure of an unknown compound by comparing the spectra achieved with standard data. 


\section{RESULTS AND DISCUSSION}

\section{Significance of Various Parameters in Proximate Analysis}

Fixed Carbon: It is the main heat generator during combustion. From the Table I Eucalyptus used to obtain bio-fuel having value of fixed carbon nearer to the poultry pure waste (around 26\%)(Singh, Sapra, and Sidhu 2013).

TABLE I Proximate analysis of eucalyptus leaves powder sample (\%).

\begin{tabular}{l|llll}
\hline Name of sample & Volatile matter (\%) & Fixed carbon (\%) & Ash content (\%) & Moisture content (\%) \\
\hline Eucalyptus leaves powder & 61.70 & 26.37 & 8.36 & 3.57 \\
\hline
\end{tabular}

Volatile Matter: Its presence is undesirable and ranges between 22 to 55\%. From Table I, almost all the raw materials are having volatile matter more than 50\%, which may help in ease in ignition, requirement of secondary air requirements etc. Higher value of volatile matters may cause higher emission of NOX, carbon monoxide etc.(Onochie et al. 2017).

Ash Content: Ash, another most undesirable constituent, is an impurity that will not burn and ranges between 2 to $40 \%$. Ash increases handling costs, affects combustion efficiency and boiler efficiency, causes clinkering and slagging and reduces burning capacity. From Table I the Eucalyptus leaf powder contains $8.36 \%$ ash(Singh, Sapra, and Sidhu 2013).

Moisture Content: Its typical range is $1 \%$ to $40 \%$. The collected Eucalyptus having percentage moisture content are in the range (less than 10\%) and hence it is a sign of good solid fuel(Onochie et al. 2017).

\section{Significance of Various Parameters in Ultimate Analysis}

Each of the constituents calculated using ultimate analysis and its role is discussed below;

TABLE II Elemental analysis (wt\%) and higher heating value (HHV) of eucalyptus leaves biomass.

\begin{tabular}{l|llllll}
\hline Name of sample & Carbon $(\%)$ & $\boldsymbol{H}_{2}(\%)$ & Nitrogen (\%) & Oxygen (\%) & Sulfur (\%) & HHV (MJ/kg) \\
\hline $\begin{array}{l}\text { Eucalyptus leaves } \\
\text { powder }\end{array}$ & 89.17 & 7.56 & 1.01 & 1.98 & 0.28 & 32.814 \\
\hline
\end{tabular}

Carbon: It plays an important role in the selection of fuel. From Table II, Eucalyptus leaf powder and charcoal possessed almost same value of percentage carbon and having almost same heating value $(-32 \mathrm{MJ} / \mathrm{kg})$ (ÖzyuğUran and Yaman 2017). 
Hydrogen: In the solid material, it is available in the combined form with the oxygen is known as inherent moisture. From Table II, the Eucalyptus leaf powder possesses around $7.5 \%$ of hydrogen(ÖzyuğUran and Yaman 2017).

Oxygen: Lower value of percentage oxygen is desirable as it reduces free hydrogen available for heating purpose. Eucalyptus leaf powder used to obtain bio-fuel having value of oxygen is nearer to $1.98 \%$ which is less compare to charcoal(ÖzyuğUran and Yaman 2017).

Sulphur: Sulphur affects clinkering and slagging tendencies, corrodes chimney and other equipment such as air heaters and economizers, cause for air pollution and limits exit flue gas temperature (Shen et al. 2010).Eucalyptus leaf powder used to obtain bio-fuel having value of sulphur around $0.28 \%$ which is less than that of charcoal $(1 \%)$ hence desirable.

Nitrogen: It does not play any important role in combustion as it has no heating value. From Table II, Eucalyptus leaf powder used to obtain biofuel having highest value of nitrogen around $1.01 \%$.

\section{Biodiesel Properties and Comparison with Standards}

TABLE III Chemical parameters of Eucalyptus Biodiesel

\begin{tabular}{l|llll}
\hline Sr No & Chemical parameter & $\begin{array}{l}\text { Specified } \\
\text { Requirement }\end{array}$ & Results & Test Method \\
\hline 1 & Flash Point $\left({ }^{\circ} \mathrm{C}\right)$ & Min. 120 & 60 & IS 1448 (PART-21):1992 \\
2 & Density at $15\left({ }^{\circ} \mathrm{C}\right), \mathrm{kg} / \mathrm{m}^{3}$ & $860-900$ & 790 & IS 1448 (PART-16):1990 \\
3 & Kinematic Viscosity at $40\left({ }^{\circ} \mathrm{C}\right), \mathrm{cSt}$ & $2.5-6.0$ & 5.83 & IS 1448 (PART-25):1976 \\
4 & Cetane Number & Min. 51 & 54 & IS 1448 (PART-9) \\
5 & Acid value, $\mathrm{mg} \mathrm{KOH} / \mathrm{gm}$ & N.A. & 0.61 & IS 1448 (PART-1):2002 \\
6 & Calorific Value, $\mathrm{kcal} / \mathrm{kg}$ & N.A. & 7850.20 & ASTM D 4868 \\
7 & Kinematic Viscosity at $100\left({ }^{\circ} \mathrm{C}\right), \mathrm{mm}^{2} / \mathrm{s}$ & N.A. & 2.03 & IS 1448 \\
\hline
\end{tabular}

The obtained Eucalyptus biodiesel is having Cetane number of 54 which may cause easy ignition of Eucalyptus biodiesel(Knothe 2008).From Table III, following points are worth noting;

1) The obtained Eucalyptus biodiesel is having kinematic viscosity at $400 \mathrm{C}=5.83 \mathrm{~mm}^{2} / \mathrm{sec}$ and density of $790 \mathrm{Kg} / \mathrm{m}^{3}$. The kinematic viscosity of obtained biodiesel is comparable with existing diesel and hence ease in atomization of biodiesel is possible(Knothe 2008). This may cause better thermal efficiency and lower value of specific fuel consumption.

2) For the Eucalyptus biodiesel, higher density and lower calorific value compared to the diesel may give low power output and torque(Barabás and Todorut 2011). 
3) Eucalyptus biodiesel may contain very less number of $\mathrm{SO}_{\mathrm{X}}$ and $\mathrm{NO}_{\mathrm{X}}$ and hence emission of $\mathrm{SO}_{\mathrm{X}}$ and $\mathrm{NO}_{\mathrm{X}}$ is almost negligible.

4) Eucalyptus biodiesel has good lubricant properties compared to diesel with small amount of sulfur which is very important to reduce wear in the engine and injection system.

\section{The influence of temperature on the product yields}

\section{Pyro-oil yield}

Figure 2 indicates the pyro-oil product at various pyrolysis temperatures. From this figure, it is understood that the yield of fuel has increased as the temperature rises to $350^{\circ} \mathrm{C}$. Above $350{ }^{\circ} \mathrm{C}$, a further rise in temperature led to a decrease in bio-oil yield. This is because the second reaction of the bio-oil to produce more gas and char is sprayed above $350{ }^{\circ} \mathrm{C}$. Other researchers have reported similar results(Fagbemi, Khezami, and Capart 2001).

\section{Bio-char yield}

Figure 3 shows the outcome of heat on the char product during pyrolysis of eucalyptus samples. It can be seen in the same person; the yield of char decreases with a temperature of up to $360{ }^{\circ} \mathrm{C}$ for all biomass sizes. This is possible because of the truth that the kinetics of the conversion of volatiles into volatiles was improved with increasing temperature. It has been suggested by some researchers that rising temperatures reduce shear yields (Fagbemi, Khezami, and Capart 2001).

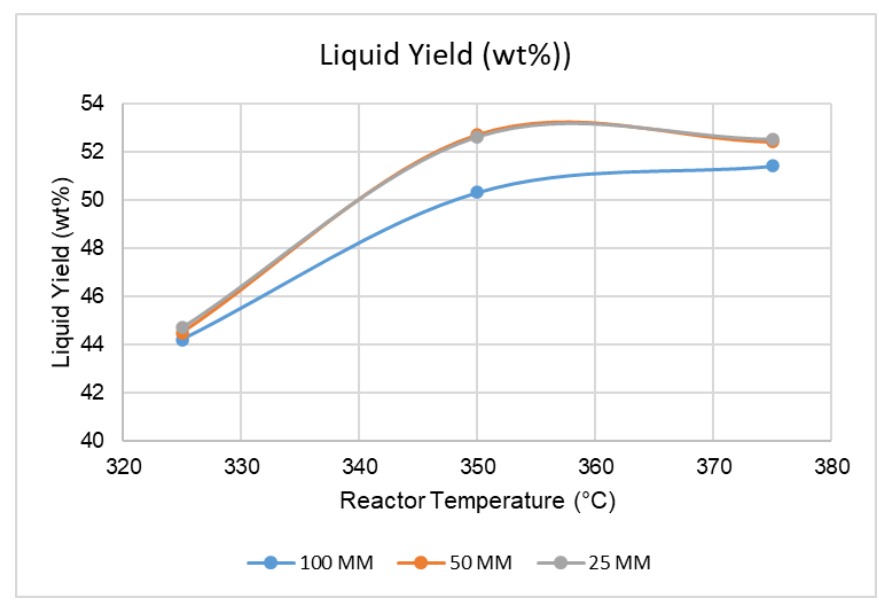

Fig 2 Bio-diesel yield at different reactor temperature. 


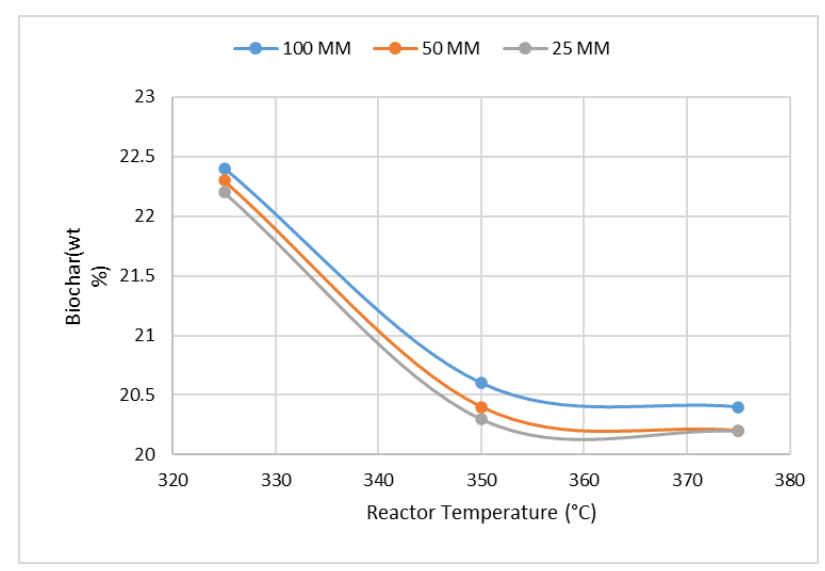

Fig 3 Bio-char yield at different reactor temperature.

\section{Bio-gas yield}

Figure 4 shows the thermal effect on biogas production from pyrolysis of eucalyptus samples. It was observed that as the temperature increased from 355 to $375^{\circ} \mathrm{C}$ the yield of pyro-gas increased by samples by biomass sizes of 25 and $50 \mathrm{~mm}$, both samples followed the same pattern, except for that sample with a size of $100 \mathrm{~mm}$ biomass.

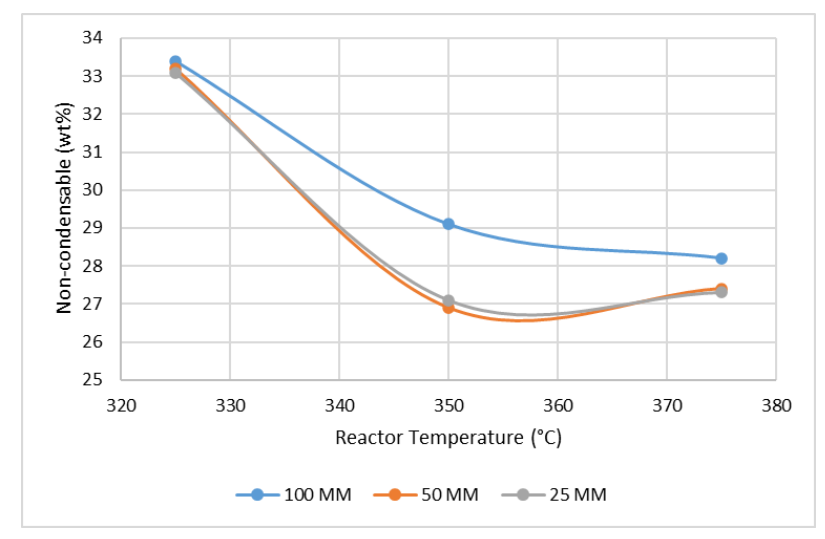

Fig 4 Pyro-gas yield at different reactor temperature

\section{Eucalyptus Biodiesel Analysis using Gas Chromatography_ Mass Spectrometry}

While the instrument is running, the computer generates a graph from the signal as shown in Fig. 5. This graph is called a chromatogram. The height of each chromatogram shows the signal formed when the compound moves from the GC column to the detector. The x-axis indicates RT, while the 
y-axis indicates the strength (\% area) of the signal. In Fig. 5, there are several peaks marked with their RTs. Each height represents each compound separated by a sample mixture. In a GC

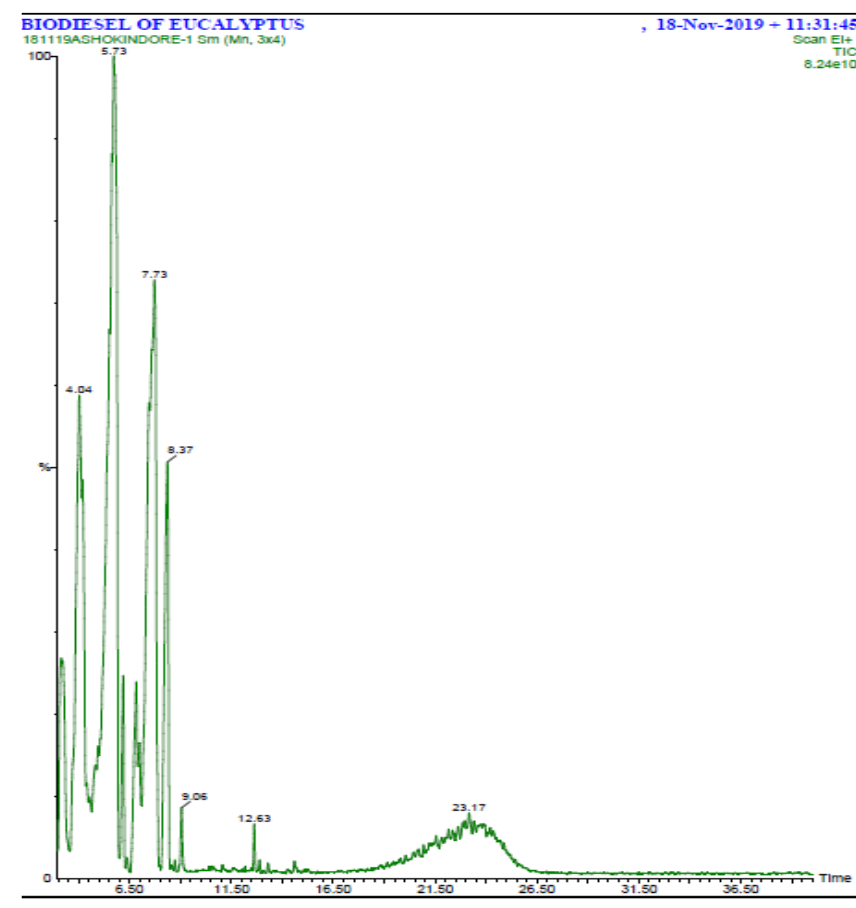

chromatogram, the total area and tot

al area of objects are equal to the fractional part of the detector

Fig 5 Chromatogram generated by a GC.

From the Fig.5 and Table IV, the peak having retention time (RT) 4.04 having area of 297419776 units with the peak height of 971220048 units and covers approximate $14.56 \%$ area. Upon analysis using mass spectrometry, it is observed Bicyclo [2.2.1heptane 2,2,3-Trimethyl $(\mathrm{C} 10 \mathrm{H} 18)$ and Cyclopentanol 1-(Methylene cyclopropyl) $\left(\mathrm{C}_{9} \mathrm{H}_{14} \mathrm{O}\right)$. The results are showing that the maximum reverse rate is also highest in $\mathrm{C}_{10} \mathrm{H}_{18}$ and hence $\mathrm{C}_{10} \mathrm{H}_{18}$ can be the one of the major component in eucalyptus biodiesel with RT 4.04(Chiu and Kuo 2020; Bunushree et al. 2019).

The second peak having retention time (RT) 5.735 having area of 770337280 units with the peak height of 681341952 units and covers approximate $31.64 \%$ area. Upon analysis using mass spectrometry, it is observed 3,4-Dihydro-2 $\mathrm{H}, 1$ ' $\mathrm{H}-\left[2,2^{\prime}\right]$ Bipyrrolyl $\left(\mathrm{C}_{8} \mathrm{H}_{18} \mathrm{~N}_{2}\right)$ and Trans-P-Mentha2,8-Dienol $\left(\mathrm{C}_{10} \mathrm{H}_{16} \mathrm{O}\right)$. The results are showing that the maximum reverse rate is also highest in 
$\mathrm{C}_{8} \mathrm{H}_{10} \mathrm{~N}_{2}$ and hence $\mathrm{C}_{8} \mathrm{H}_{10} \mathrm{~N}_{2}$ can be the one of the major components in eucalyptus biodiesel with $\mathrm{RT}$ 5.735 .

The third peak having retention time (RT) 7.73 having area of 807475712 units with the peak height of 376151040 units and covers approximate $22.12 \%$ area. Upon analysis using mass spectrometry, it is observed $2(1 \mathrm{H})$-Naphthalene, 4A,5,6,7,8,8A-Hexahyedro-4A,8A-Dimethyl-, CIS- $\left(\mathrm{C}_{12} \mathrm{H}_{18} \mathrm{O}\right)$ and Acetaldehyde, (3,3-Dimethylcyclohexylidene)-, $(\mathrm{E})-\left(\mathrm{C}_{10} \mathrm{H}_{16} \mathrm{O}\right)$. The results are showing that the maximum reverse rate is also highest in $\mathrm{C}_{12} \mathrm{H}_{18} \mathrm{O}$ and hence $\mathrm{C}_{12} \mathrm{H}_{18} \mathrm{O}$ can be the one of the major components in eucalyptus biodiesel with RT 7.73 .

The fourth peak having retention time (RT) 8.41 having area of 849509376 units with the peak height of 753283072 units and covers approximate $7.04 \%$ area. Upon analysis using mass spectrometry, it is observed Picolinyl, 6-CIS,10-TRANS,12-CIS-Octadecatrienoate $\left(\mathrm{C}_{24} \mathrm{H}_{35} \mathrm{O}_{2} \mathrm{~N}\right)$ and 9,12,15-Octadecatrienoic acid, Methyl ester, (Z, Z, Z) $\left(\mathrm{C}_{19} \mathrm{H}_{32} \mathrm{O}_{2}\right)$ and Cyclopentanol, 3-Methyl-2-(2Pentenyl) $\left(\mathrm{C}_{11} \mathrm{H}_{20} \mathrm{O}\right)$. The results are showing that the maximum reverse rate is also highest in $\mathrm{C}_{24} \mathrm{H}_{35} \mathrm{O}_{2} \mathrm{~N}$ and hence $\mathrm{C}_{24} \mathrm{H}_{35} \mathrm{O}_{2} \mathrm{~N}$ can be the one of the major components in eucalyptus biodiesel with RT 8.41.

The fifth peak having retention time (RT) 23.167 having area of 450790912 units with the peak height of 753283072766666240 units and covers approximate $13.88 \%$ area. Upon analysis using mass spectrometry, it is observed 11-Tricosene $\left(\mathrm{C}_{23} \mathrm{H}_{46}\right)$ and17-Pentatriacontene $\left(\mathrm{C}_{35} \mathrm{H}_{70}\right)$ and 2Piperidinone, N-[4-Bromo-N-Butyl]- $\left(\mathrm{C}_{9} \mathrm{H}_{16} \mathrm{ONBr}\right)$. The results are showing that the maximum reverse rate is also highest in $\mathrm{C}_{23} \mathrm{H}_{46}$ and hence $\mathrm{C}_{23} \mathrm{H}_{46}$ can be the one of the major components in eucalyptus biodiesel with RT 23.167.

TABLE IV Compounds Detected from TIC Diesel Fuel Standard

\begin{tabular}{|c|c|c|c|c|}
\hline $\begin{array}{l}\mathrm{Sr} \\
\text { No }\end{array}$ & Name & $\overline{R T}$ & Area & Area\% \\
\hline 1 & $\begin{array}{l}\text { Bicyclo[2.2.1 heptane2,2, } \\
\text { 3-Trimethyl }\left(\mathrm{C}_{10} \mathrm{H}_{18}\right) \\
\text { and Cyclopentanol } \\
\text { 1-(Methylene cyclopropyl) } \\
\left(\mathrm{C}_{9} \mathrm{H}_{140}\right)\end{array}$ & 4.044 & 297419776 & 14.56 \\
\hline 2 & $\begin{array}{l}\text { 3,4-Dihydro-2H,1'H-[2,2'] } \\
\text { Bipyrrolyl }\left(\mathrm{C}_{8} \mathrm{H}_{18} \mathrm{~N}_{2}\right) \text { and } \\
\text { Trans-P-Mentha-2,8- } \\
\text { Dienol }\left(\mathrm{C}_{10} \mathrm{H}_{16} \mathrm{O}\right)\end{array}$ & 5.735 & 770337280 & 31.64 \\
\hline 3 & $\begin{array}{l}\text { 2(1H)-Naphthalenone, } \\
\text { 4A,5,6,7,8,8A- } \\
\text { Hexahyedro-4A,8A- } \\
\text { Dimethyl-, }\end{array}$ & 7.730 & 807475712 & 22.12 \\
\hline
\end{tabular}




\begin{tabular}{|c|c|c|c|c|}
\hline & $\begin{array}{l}(\mathrm{C} 12 \mathrm{H} 180) \text { and } \\
\text { Acetaldehyde, } \\
\text { Dimethylcyc lohexylidene)- } \\
,(\mathrm{E})-\left(\mathrm{C}_{10} \mathrm{H}_{16} \mathrm{O}\right)\end{array}$ & & & \\
\hline 4 & $\begin{array}{lr}\text { Picolinyl, } & \text { 6-CIS,10- } \\
\text { TRANS,12-CIS- } & \\
\text { Octadecatrienoate } & \\
\left(\mathrm{C}_{24} \mathrm{H}_{35} \mathrm{O}_{2} \mathrm{~N}\right) \text { and } & 9,12,15- \\
\text { Octadecatrienoic } & \text { acid, } \\
\text { Methyl ester, } & (\mathrm{Z}, \mathrm{Z}, \mathrm{Z}) \\
\left(\mathrm{C}_{19} \mathrm{H}_{32} \mathrm{O}_{2}\right) & \text { and } \\
\text { Cyclopentanol, } & \text { 3-Methyl- } \\
\text { 2-(2-Pentenyl) }\left(\mathrm{C}_{11} \mathrm{H}_{20} \mathrm{O}\right)\end{array}$ & 8.371 & 849509376 & 7.04 \\
\hline 5 & $\begin{array}{l}\text { 11-Tricosene }\left(\mathrm{C}_{23} \mathrm{H}_{46}\right) \\
\text { and } \\
\text { 17-Pentatriacontene } \\
\left(\mathrm{C}_{35} \mathrm{H}_{70}\right) \text { and 2- } \\
\text { Piperidinone, N-[4-Bromo- } \\
\text { N-Butyl]- }\left(\mathrm{C}_{9} \mathrm{H}_{16} \mathrm{ONBr}\right)\end{array}$ & 23.167 & 450790912 & 13.88 \\
\hline
\end{tabular}

\section{SWOT analysis of eucalyptus biodiesel}

A detailed SWOT analysis performed on eucalyptus biodiesel.

Strength:

- Large amount of eucalyptus leaves is available as a wastage.

- The leaves are not useful at all for any purpose.

- It is second generation feed stock.

Weakness:

- Required fertilized land and clean water.

- Take minimum 01 to 02 years for growth of the tree.

- It is a region-specific crop.

Opportunity:

- Very large market from automobile and power sector is ready to use the alternative solution.

- Very less research has been carried out in the above field. 
Threat:

- Policy related to biodiesel distribution and production has been not clearly formulated by the higher authorities.

- Biodiesel production from other feed stocks can be captured the market.

- Least awareness among the end users about biodiesel.

- Lots of fake myths about biodiesel among the customers.

\section{CONCLUSION}

The ability of the Gujarat-India energy depletion system has been tested by looking at the production of pyrolysis products from fresh eucalyptus leaves. The chemical composition of the rapid pyrolysis biodiesel from the samples was also studied in the GC-MS analysis. The results showed that there was a difference in bio-diesel composition from the studied samples. These include different levels of phenolic chemicals, oleic acids, aromatic hydrocarbons, and nitrogen-containing compounds.

Percentage of carbon is highest in the charcoal and having higher heating value. Eucalyptus leaf powder and charcoal possessed almost same value of percentage carbon and having almost same heating value $(32 \mathrm{MJ} / \mathrm{kg})$. Proxi mate analysis of eucalyptus leaves powder sample shows that volatile matter, fixed carbon, ash content and moisture content are $61.70 \%, 26.37 \%, 8.36 \%$ and 3.57\%, The results of the elemental analysis show that the contents of carbon, hydrogen, nitrogen, oxygen and sulfur are $89.17 \%, 7.36 \%, 1.01 \%, 1.98 \%$ and $0.26 \%$, respectively. This information will be of great value in assessing the sustainability of bio-oil, sufficient fuel supplies, toxins and potential chemical sources. It will also help determine what steps to take in refining bio-diesel into liquid fuel. Test results prove that various elements contained by solid Eucalyptus leaf powder and chemical constituents of them were comparable and in desirable range with respect to various feed stocks or crops used for derivation of biofuel.

\section{REFERENCES}

Balat, Mustafa, Mehmet Balat, Elif Kirtay, and Havva Balat. 2009. "Main Routes for the Thermo-Conversion of Biomass into Fuels and Chemicals. Part 1: Pyrolysis Systems.” Energy $\begin{array}{lllll}\text { Conversion } & \text { and } & \text { Management } & 50 & \text { (12): }\end{array}$ 
https://doi.org/10.1016/j.enconman.2009.08.014.

Barabás, István, and Ioan-Adrian Todorut. 2011. "Biodiesel Quality, Standards and Properties." Biodiesel: Quality, Emissions and by-Products, 3-28. https://doi.org/10.5772/25370.

Bunushree, B., B. Ravichandra, S. Rangabhashiyam, R. Jayabalan, and P. Balasubramanian. 2019. "Qualitative Analysis of Biodiesel Produced by Alkali Catalyzed Transesterification of Waste Cooking Oil Using Different Alcohols.” Indian Journal of Chemical Technology 26 (4): 330-36.

Chiu, Huai Hsuan, and Ching Hua Kuo. 2020. “Gas Chromatography-Mass SpectrometryBased Analytical Strategies for Fatty Acid Analysis in Biological Samples." Journal of Food and Drug Analysis 28 (1): 60-73. https://doi.org/10.1016/j.jfda.2019.10.003.

Fagbemi, L., L. Khezami, and R. Capart. 2001. "Pyrolysis Products from Different Biomasses: Application to the Thermal Cracking of Tar." Applied Energy 69 (4): 293-306. https://doi.org/10.1016/S0306-2619(01)00013-7.

Joshi, Piyush, Neeta Sharma, and Priyangshu Manab Sarma. 2015. "Assessment of Biomass Potential and Current Status of Bio-Fuels and Bioenergy Production in India." Current Biochemical Engineering 3 (1): 4-15. https://doi.org/10.2174/2212711902999150923155545.

Kaushik, Nirmala, and Sanjay Singh. 2016. "Opportunities for Bio Fuels - Indian Scenario." Procedia Environmental Sciences 35: 847-52. https://doi.org/10.1016/j.proenv.2016.07.101.

Knothe, Gerhard. 2008. "Biodiesel Composition and Fuel Properties," 1-62.

Moussa, Rashid, and Ahmad Fayez Alzeibak. 2014. "Missions of Ethanol Fueled Engine and Carcinogenic Gases." Journal of Engineering Research 2 (4): 119-35. https://doi.org/10.7603/s40632-014-0028-6.

Onochie, U P, A I Obanor, S A Aliu, and O O Igbodaro. 2017. "Proximate and Ultimate Analysis of Fuel Pellets From Oil Palm Residues.” Nigerian Journal of Technology 36 (3): 987-90.

Onsree, Thossaporn, Nakorn Tippayawong, Anqing Zheng, and Haibin Li. 2018. "Pyrolysis Behavior and Kinetics of Corn Residue Pellets and Eucalyptus Wood Chips in a Macro Thermogravimetric Analyzer." Case Studies in Thermal Engineering 12 (July): 546-56. 
https://doi.org/10.1016/j.csite.2018.07.011.

Oyebanji, J. A., P. O. Okekunle, O. A. Lasode, and S. O. Oyedepo. 2018. "Chemical Composition of Bio-Oils Produced by Fast Pyrolysis of Two Energy Biomass." Biofuels 9 (4): 479-87. https://doi.org/10.1080/17597269.2017.1284473.

ÖzyuğUran, Ayşe, and Serdar Yaman. 2017. "Prediction of Calorific Value of Biomass from Proximate Analysis." Energy Procedia 107 (September 2016): 130-36. https://doi.org/10.1016/j.egypro.2016.12.149.

Patel, Ashok, Basant Agrawal, and B R Rawal. 2020. "Pyrolysis of Biomass for Efficient Extraction of Biofuel." Energy Sources, Part A: Recovery, Utilization, and Environmental Effects 42 (13): 1649-61. https://doi.org/10.1080/15567036.2019.1604875.

Purohit, Pallav, and Vaibhav Chaturvedi. 2018. "Biomass Pellets for Power Generation in India: A Techno-Economic Evaluation.” Environmental Science and Pollution Research 25 (29): 29614-32. https://doi.org/10.1007/s11356-018-2960-8.

Shen, Jianfeng, Shuguang Zhu, Xinzhi Liu, Houlei Zhang, and Junjie Tan. 2010. "The Prediction of Elemental Composition of Biomass Based on Proximate Analysis." Energy Conversion and Management 51 (5): 983-87. https://doi.org/10.1016/j.enconman.2009.11.039.

Singh, Harmandeep, Kumar Pawan Sapra, and Balwinder Singh Sidhu. 2013. "Evaluation and Characterization of Different Biomass Residues through Proximate \&amp; Ultimate Analysis and Heating Value.” Asian Journal of Engineering and Applied Technology 2 (2): 6-9.

Suttibak, Suntorn. 2017. "Influence of Reaction Temperature on Yields of Bio-Oil from Fast Pyrolysis of Sugarcane Residues.” Engineering and Applied Science Research 44 (3): 142-47. https://doi.org/10.14456/easr.2017.21.

Zhang, Linghong, Chunbao (Charles) Xu, and Pascale Champagne. 2010. "Overview of Recent Advances in Thermo-Chemical Conversion of Biomass." Energy Conversion and Management 51 (5): 969-82. https://doi.org/10.1016/j.enconman.2009.11.038. 